\title{
Kinetics and Mechanism of Ruthenium(III)-Catalyzed Oxidation of L-citrulline by Hexachloroplatinate(IV) in Perchloric Acid
}

\author{
Ahmed Fawzy ${ }^{1,2}$, Ishaq A. Zaafarany ${ }^{1}$, Ismail I. Althagafi ${ }^{1}$, Hatem M. Altass ${ }^{1}$, Moataz H. Morad ${ }^{1}$, \\ Fahd A. Tirkistani ${ }^{1}$ \\ ${ }^{1}$ Chemistry Department, Faculty of Applied Science, Umm Al-Qura University, Makkah, Saudi Arabia \\ ${ }^{2}$ Chemistry Department, Faculty of Science, Assiut University, Assiut, Egypt
}

Email address:

afsaad13@yahoo.com (A. Fawzy), iazaafarany@uqu.edu.sa (I. A. Zaafarany), iithagafi@uqu.edu.sa (I. I. Althagafi), hatem1401@hotmail.com (H. M. Altass),mhmorad@uqu.edu.sa (M. H. Morad), drfahd999@gmail.com (F. A. Tirkistani)

\section{To cite this article:}

Ahmed Fawzy, Ishaq A. Zaafarany, Ismail I. Althagafi, Hatem M. Altass, Moataz H. Morad, Fahd A. Tirkistani. Kinetics and Mechanism of Ruthenium(III)-Catalyzed Oxidation of L-citrulline by Hexachloroplatinate(IV) in Perchloric Acid. Science Journal of Chemistry.

Vol. 4, No. 5, 2016, pp. 53-60. doi: 10.11648/j.sjc.20160405.11

Received: August 29, 2016; Accepted: September 5, 2016; Published: September 24, 2016

\begin{abstract}
Oxidation kinetics of L-citrulline (Cit) by hexachloroplatinate(IV) (HCP) was studied spectrophotometrically in perchloric acid solutions in the presence of ruthenium(III) catalyst at a constant ionic strength of $1.8 \mathrm{~mol} \mathrm{dm}^{-3}$ and at $20^{\circ} \mathrm{C}$. The reaction rate was very slow in the absence of the catalyst. The reaction showed first order kinetics in both $[\mathrm{HCP}]$ and $[\mathrm{Ru}(\mathrm{III})]$ and less than unit order with respect to both $[\mathrm{Cit}]$ and $\left[\mathrm{H}^{+}\right]$. Increasing ionic strength and dielectric constant were found to increase the oxidation rate. Both spectral and kinetic evidences revealed formation of an intermediate complex between Lcitrulline and ruthenium(III) prior to the rate-determining step. The complex reacts with the oxidant (HCP) by an inner-sphere mechanism leading to decomposition of the complex in the rate-determining step to give rise to the final oxidation products of L-citrulline which were identified by both spectroscopic and chemical tools as 4-(carbamoylamino) butyraldehyde, ammonia and carbon dioxide. The rate-law expression for the catalyzed reaction was deduced. The reaction constants involved in the different steps of the reaction mechanism have been evaluated. The activation parameters of the second order rate constant have been evaluated and discussed.
\end{abstract}

Keywords: L-Citrulline, Hexachloroplatinate(IV), Ruthenium(III), Oxidation, Kinetics, Mechanism

\section{Introduction}

Oxidation of amino acids is considered as a significant field of organic chemistry because of its bearing on the mechanism of amino acid metabolism. Kinetics of oxidation of amino acids by various oxidants in different media has been studied earlier [1-18], and they often undergo oxidative decarboxylation and deamination. L-citrulline (2-amino-5(carbamoylamino) pentanoic acid, shown below) is a naturally occurring amino acid which is used for Alzheimer's disease, dementia, fatigue, muscle weakness, high blood pressure, and diabetes. It is also used for heart disease, body building, increasing energy, and for improving athletic performance. L-citrulline might help increase the supply of ingredients the body needs to making certain proteins. It is a key intermediate in the urea cycle. In the body, L-citrulline is produced as a byproduct of the enzymatic production of nitric oxide from the amino acid arginine, catalyzed by nitric oxide synthase [19].<smiles>NC(=O)NCCCC(N)C(=O)O</smiles>

Biologically active platinum (IV) complexes such as hexachloroplatinate (IV) complex (HCP), $\left[\mathrm{PtCl}_{6}\right]^{2-}$, have remarkable anticancer properties [20-23]. They have become attractive because they are usually substitution-inert, hence requiring reduction to $\mathrm{Pt}$ (II) species before they can act as 
potential anticancer drugs. Their reduction with different reductants generally proceeds via a free radical one-electron transfer mechanism [24, 25]. An alternative path, whereby $\mathrm{Pt}$ (IV) undergoes a two-electron reduction process was also shown to occur [26]. The experimental conditions and choice of reductant determined whether a two-electron reduction process could occur. Hexachloroplatinate (IV) complex has been used to oxidize a limited number of inorganic [23-29] and organic [10-16, 30-34] compounds in different media. The knowledge of the reactivity of platinum (IV) compounds towards their reduction by potential bioreductant such as Lcitrulline may be important for understanding the mechanism of where antitumor activity as well as for designing new compounds with the least side effect. Furthermore, transition metal ions have been widely employed as homogenous catalysts for oxidation of organic and inorganic substrates [816] by different reaction pathways such as formation of complexes with the reactants, oxidation of a substrate, or the formation of free radicals [35]. Kinetic investigations on the oxidation of amino acids catalyzed by different metal ions are an important field of chemistry due to the role played by metals in biological systems.

Literature survey reveals that there are no reports about the kinetics of oxidation of L-citrulline by any oxidant. In view of the above mentioned arguments, we have carried out a detailed study on the kinetics and mechanism of oxidation of this amino acid by hexachloroplatinate (IV) in perchloric acid medium in the presence of ruthenium (III) catalyst. This work aims to study the selectivity of the studied amino acid towards HCP in an acid medium, to check the catalytic efficiency of $\mathrm{Ru}$ (III) catalyst, and to elucidate a suitable oxidation mechanism.

\section{Experimental}

\subsection{Materials}

A stock solution of L-citrulline was prepared afresh by dissolving the sample (SD. Fine Chem.) in bidistilled water. Chloroplatinic acid solution (Johnson Matthey) was used without further purification. Required solution of the oxidant was freshly prepared before each experiment by proper dilution of its original solution which is standardized spectrophotometrically [36]. The solution was stored in a bottle away from light and re-standardized periodically. Sodium perchlorate and acetic acid were used to vary the ionic strength and dielectric constant of the reaction medium, respectively.

\subsection{Kinetic Measurements}

All kinetic investigations were performed under pseudofirst-order conditions where L-citrulline was present in a large excess over that of HCP. The ionic strength, $I$, of the reaction mixture was adjusted to $1.8 \mathrm{~mol} \mathrm{dm}^{-3}$ using sodium perchlorate as an inert electrolyte. The reaction temperature $\left(20^{\circ} \mathrm{C}\right)$ was controlled within $\pm 0.1^{\circ} \mathrm{C}$ unless stated otherwise. The reaction was initiated by rapid addition of known amounts of the pre-equilibrated HCP to the reaction mixture containing the required amounts of L-citrulline, perchloric acid, $\mathrm{Ru}$ (III) chloride, sodium perchlorate and water, thermostated at the same temperature. The solutions were then mixed and transferred to a cell with a path length of 1.0 $\mathrm{cm}$. The course of the reaction was followed spectrophotometrically by monitoring the decrease in the absorbance of HCP at $\lambda=262 \mathrm{~nm}$, its absorption maximum, as a function of time using Shimadzu UV-VIS-NIR-3600 double-beam spectrophotometer with a cell compartment kept at constant temperature. The applicability of Beer's law was verified at $262 \mathrm{~nm}$ under the reaction conditions. The molar extinction coefficient, $\varepsilon$, was determined $(\varepsilon=(1.319 \pm$ $0.07) \times 10^{4} \mathrm{dm}^{3} \mathrm{~mol}^{-1} \mathrm{~cm}^{-1}$ ) and was found to be in a good agreement with that reported previously [36]. In addition, there is no interference from other reagents at this wavelength. It was observed that the oxidation reaction was very slow in the absence of $\mathrm{Ru}$ (III) catalyst. The pseudo-first order rate constant values of the catalyzed reaction $\left(k_{\mathrm{C}}\right)$ were obtained from the linear portion of $\ln$ (absorbance) versus time plots, which were the average of at least two independent kinetics runs and were reproducible to within $\pm 3 \%$. Double logarithmic plots were used to determine the order with respect to each reactant. The concentration of the particular species being examined was varied while the concentrations of the other species were held fixed.

\section{Results}

\subsection{Spectral Changes}

The spectral changes during the course of the reaction between L-citrulline and HCP in the presence of $\mathrm{Ru}(\mathrm{III})$ catalyst are shown in Figure 1. The scanned spectra indicate gradual disappearance of the HCP absorption band with time as a result of its reduction. Two isosbestic points located at 242 and $305 \mathrm{~nm}$ are apparent in the spectra.

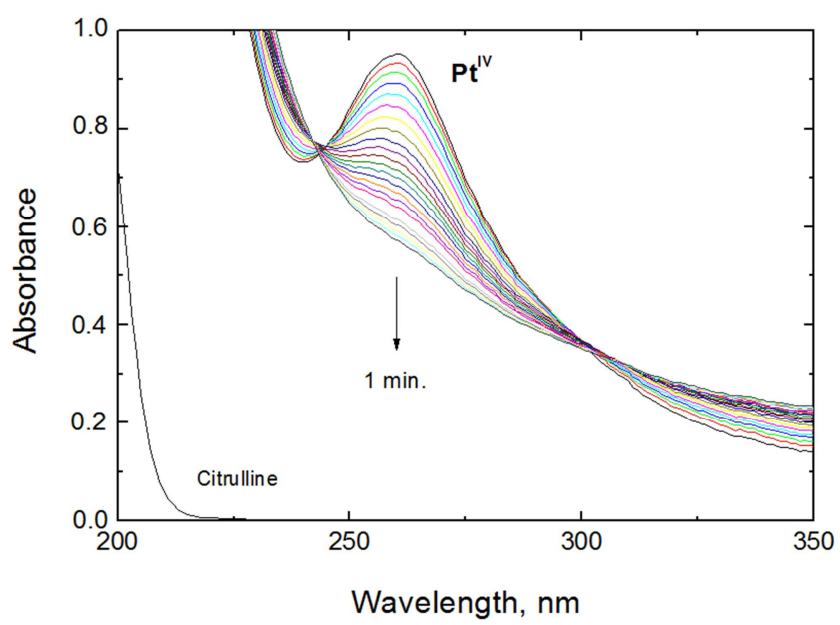

Figure 1. Time-resolved spectra during Ru(III)-catalyzed oxidation of Lcitrulline by HCP in perchloric acid solution. [Cit] $=6.0 \times 10^{-3}$, [HCP] $=$ $8.0 \times 10^{-5},\left[\mathrm{H}^{+}\right]=1.0,[\mathrm{Ru}(\mathrm{III})]=5.0 \times 10^{-5}$ and $\mathrm{I}=1.8 \mathrm{~mol} \mathrm{dm}{ }^{-3}$ at $20^{\circ} \mathrm{C}$. Scanning time interval $=1.0 \mathrm{~min}$. 


\subsection{Reaction Stoichiometry and Product Analysis}

Different sets of the reaction mixtures with different sets of reactants containing various amounts of $\mathrm{HCP}$ and L-citrulline at fixed acidity, ionic strength, and temperature were allowed to react for $24 \mathrm{~h}$ in an inert atmosphere. After completion of the reactions, the unreacted $[\mathrm{HCP}]$ was determined spectrophotometrically. Results indicated that one mole of Lcitrulline consumed one mole of HCP in the predominant reaction, as represented in the following stoichiometric equation:

$$
\overbrace{\mathrm{NH}_{2}}^{\mathrm{O}} \mathrm{OH}+\left[\mathrm{PrCl}_{6}\right]^{2-}+\mathrm{H}_{2} \mathrm{O} \stackrel{\mathrm{Ru}(\mathrm{III})}{\longrightarrow}
$$<smiles>NC(=O)NCCCC=O</smiles>

The above stoichiometric equation is consistent with the results of product analysis. The oxidation products of Lcitrulline was identified as the corresponding aldehyde 4(carbamoylamino) butyraldehyde, ammonia and carbon dioxide by both spectroscopic and chemical tools as reported earlier [37, $38]$. On the other hand, formation of $\left[\mathrm{PtCl}_{4}\right]^{2-}$ was confirmed [10-16] by the observed black precipitate of platinum(II) hydroxide on addition of alkali to the reaction mixture.

\subsection{Effect of [HCP]}

The concentration of the oxidant, HCP, was varied in the range of $2.0 \times 10^{-5}$ to $12.0 \times 10^{-5} \mathrm{~mol} \mathrm{dm}^{-3}$ at constant [Cit], $[\mathrm{Ru}(\mathrm{III})],\left[\mathrm{H}^{+}\right]$, ionic strength and temperature. The nonvariation in the observed first order rate constants at various concentrations of HCP (Table 1) indicates that the order with respect to the oxidant is confirmed to be one.

\subsection{Effect of [Cit]}

The observed first order rate constant $\left(k_{\mathrm{C}}\right)$ was determined at different initial concentrations of L-citrulline substrate keeping all other reactants concentration constant including $\mathrm{Ru}$ (III) catalyst. The results showed that the rate constant increased with increase in the L-citrulline concentration as listed in Table 1. A plot of $k_{\mathrm{C}}$ versus [Cit] was found to be linear with a positive intercept indicating less than unit order dependence with respect to L-citrulline (Figure 2).

\subsection{Effect of $\left[\mathrm{H}^{+}\right]$}

The reaction rate was measured at constant [Cit], [HCP], $[\mathrm{Ru}(\mathrm{III})]$, ionic strength and temperature but with various $\left[\mathrm{H}^{+}\right]$ $\left(0.3-1.6 \mathrm{~mol} \mathrm{dm}^{-3}\right)$. The rate of reaction was found to increase as $\left[\mathrm{H}^{+}\right]$increased with less than unit order as the slope of the plot of $\log k_{\mathrm{C}}$ versus $\log \left[\mathrm{H}^{+}\right]$as illustrated in Figure 3.

\subsection{Effect of [Ru (III)]}

The reaction rate was measured with various $[\mathrm{Ru}(\mathrm{III})],(1.0$
- 11.0) $\times 10^{-5} \mathrm{~mol} \mathrm{dm}^{-3}$ at constant other variables. The reaction rate increased with the increase in $[\mathrm{Ru}(\mathrm{III})]$ (Table 1). The order with respect to $[\mathrm{Ru}(\mathrm{III})]$ was found to be unity as the slope of $\log k_{\mathrm{C}}$ versus $\log [\mathrm{Ru}(\mathrm{III})]$ plot (Figure 4).

Table 1. Effect of [HCP], [Cit], [H $\left.H^{+}\right],[R u(I I I)]$ and ionic strength, I, on the observed first order rate constant $\left(k_{C}\right)$ in the Ru(III)-catalyzed oxidation of L-citrulline by $\mathrm{HCP}$ in perchloric acid solutions at $20^{\circ} \mathrm{C}$.

\begin{tabular}{|c|c|c|c|c|c|}
\hline $\begin{array}{l}10^{5}[\mathrm{HCP}] \\
\left(\mathrm{mol} \mathrm{dm}^{-3}\right)\end{array}$ & $\begin{array}{l}10^{3}[\mathrm{Cit}] \\
\left(\mathrm{mol} \mathrm{dm}^{-3}\right)\end{array}$ & $\begin{array}{l}{\left[\mathrm{H}^{+}\right](\mathrm{mol}} \\
\left.\mathrm{dm}^{-3}\right)\end{array}$ & $\begin{array}{l}10^{5}[\mathrm{Ru}(\mathrm{III})] \\
\left(\mathrm{mol} \mathrm{dm}^{-3}\right)\end{array}$ & $\begin{array}{l}I \\
\left(\mathrm{~mol} \mathrm{dm}^{-3}\right)\end{array}$ & $\begin{array}{l}10^{5} k_{\mathrm{C}} \\
\left(\mathrm{s}^{-1}\right)\end{array}$ \\
\hline 2.0 & 6.0 & 1.0 & 5.0 & 1.8 & 15.9 \\
\hline 4.0 & 6.0 & 1.0 & 5.0 & 1.8 & 17.1 \\
\hline 6.0 & 6.0 & 1.0 & 5.0 & 1.8 & 18.3 \\
\hline 8.0 & 6.0 & 1.0 & 5.0 & 1.8 & 17.6 \\
\hline 10.0 & 6.0 & 1.0 & 5.0 & 1.8 & 17.5 \\
\hline 12.0 & 6.0 & 1.0 & 5.0 & 1.8 & 18.1 \\
\hline 8.0 & 2.0 & 1.0 & 5.0 & 1.8 & 10.2 \\
\hline 8.0 & 4.0 & 1.0 & 5.0 & 1.8 & 13.3 \\
\hline 8.0 & 6.0 & 1.0 & 5.0 & 1.8 & 17.6 \\
\hline 8.0 & 8.0 & 1.0 & 5.0 & 1.8 & 20.6 \\
\hline 8.0 & 10.0 & 1.0 & 5.0 & 1.8 & 23.9 \\
\hline 8.0 & 12.0 & 1.0 & 5.0 & 1.8 & 25.9 \\
\hline 8.0 & 6.0 & 0.3 & 5.0 & 1.8 & 9.1 \\
\hline 8.0 & 6.0 & 0.5 & 5.0 & 1.8 & 12.4 \\
\hline 8.0 & 6.0 & 0.7 & 5.0 & 1.8 & 14.6 \\
\hline 8.0 & 6.0 & 1.0 & 5.0 & 1.8 & 17.6 \\
\hline 8.0 & 6.0 & 1.3 & 5.0 & 1.8 & 21.2 \\
\hline 8.0 & 6.0 & 1.6 & 5.0 & 1.8 & 23.0 \\
\hline 8.0 & 6.0 & 1.0 & 1.0 & 1.8 & 5.1 \\
\hline 8.0 & 6.0 & 1.0 & 3.0 & 1.8 & 12.5 \\
\hline 8.0 & 6.0 & 1.0 & 5.0 & 1.8 & 17.6 \\
\hline 8.0 & 6.0 & 1.0 & 7.0 & 1.8 & 23.6 \\
\hline 8.0 & 6.0 & 1.0 & 9.0 & 1.8 & 30.4 \\
\hline 8.0 & 6.0 & 1.0 & 11.0 & 1.8 & 35.9 \\
\hline 8.0 & 6.0 & 1.0 & 5.0 & 1.8 & 17.6 \\
\hline 8.0 & 6.0 & 1.0 & 5.0 & 2.1 & 18.8 \\
\hline 8.0 & 6.0 & 1.0 & 5.0 & 2.4 & 20.5 \\
\hline 8.0 & 6.0 & 1.0 & 5.0 & 2.7 & 22.1 \\
\hline 8.0 & 6.0 & 1.0 & 5.0 & 3.0 & 23.4 \\
\hline 8.0 & 6.0 & 1.0 & 5.0 & 3.3 & 24.7 \\
\hline
\end{tabular}

Experimental error $\pm 3 \%$

\subsection{Effect of Ionic Strength and Dielectric Constant}

The effect of ionic strength on the oxidation rate was studied by the addition of sodium perchlorate to the reaction medium at constant concentration of L-citrulline, HCP, $\mathrm{Ru}(\mathrm{III})$, and at constant $\mathrm{pH}$ and temperature. The results showed that the rate constant increased with increase in the ionic strength of the medium, and the Debye-Hückel plot was found to be linear with a positive slope as shown in Figure 5. Also, the effect of the dielectric constant $(D)$ of the medium on the oxidation rate was studied at different solvent compositions $(\mathrm{v} / \mathrm{v})$ of acetic acid and water. The dielectric constant of the medium at different compositions was calculated using the dielectric constants of water and acetic acid as 78.5 and 6.15 , respectively, at $20{ }^{\circ} \mathrm{C}$. The rate constant was found to decrease with the decrease in dielectric constant of the solvent mixture, i.e., increase in acetic acid content. The plot of $\log k_{\mathrm{C}}$ versus $1 / D$ was found to be linear with a negative slope as shown in Figure 6. 


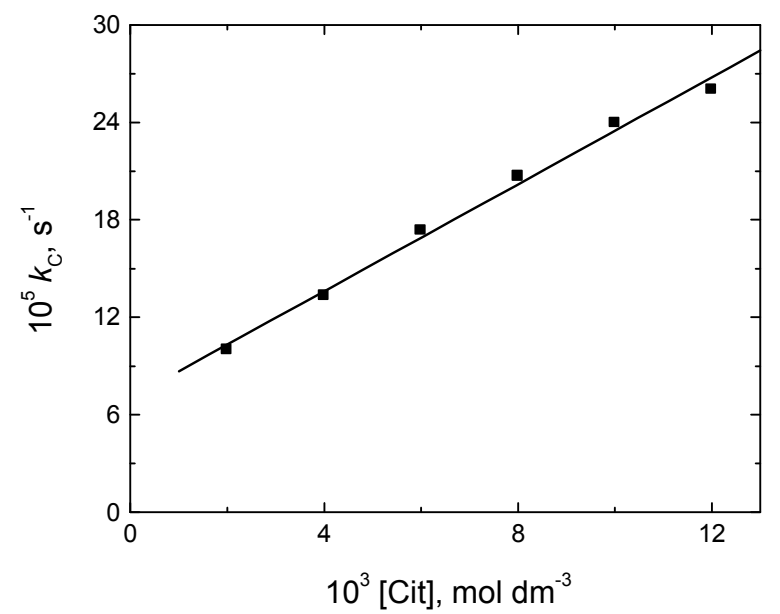

Figure 2. Plot of the observed first order rate constant ( $\left.k_{C}\right)$ versus [Cit] in the Ru(III)-catalyzed oxidation of L-citrulline by HCP in perchloric acid solution. $[H C P]=8.0 \times 10^{-5},\left[H^{+}\right]=1.0,[R u(I I I)]=5.0 \times 10^{-5}$ and $I=1.8$ mol dm $m^{-3}$ at $20^{\circ} \mathrm{C}$.

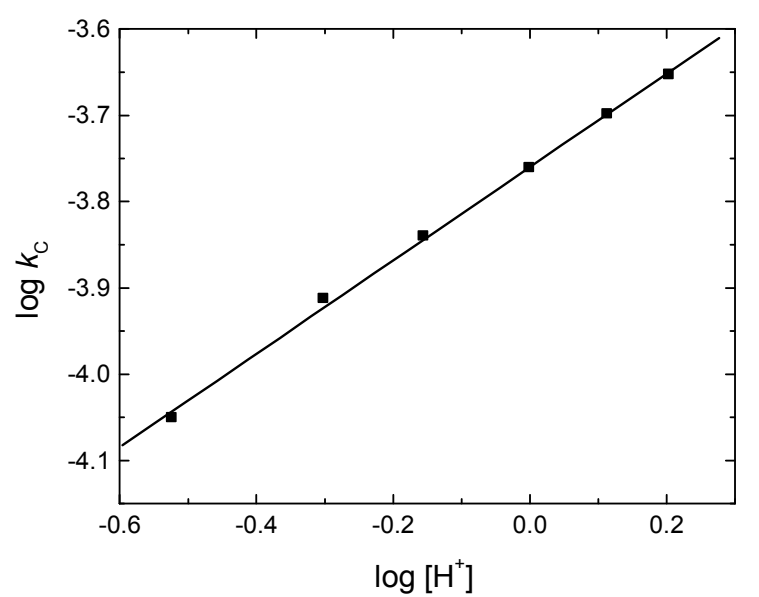

Figure 3. Plot of $\log k_{C}$ versus $\log \left[H^{+}\right]$in the Ru(III)-catalyzed oxidation of L-citrulline by HCP in perchloric acid solution. [Cit $]=6.0 \times 10^{-3},[\mathrm{HCP}]=$ $8.0 \times 10^{-5},[R u(I I I)]=5.0 \times 10^{-5}$ and $I=1.8 \mathrm{~mol} \mathrm{dm}^{-3}$ at $20^{\circ} \mathrm{C}$.

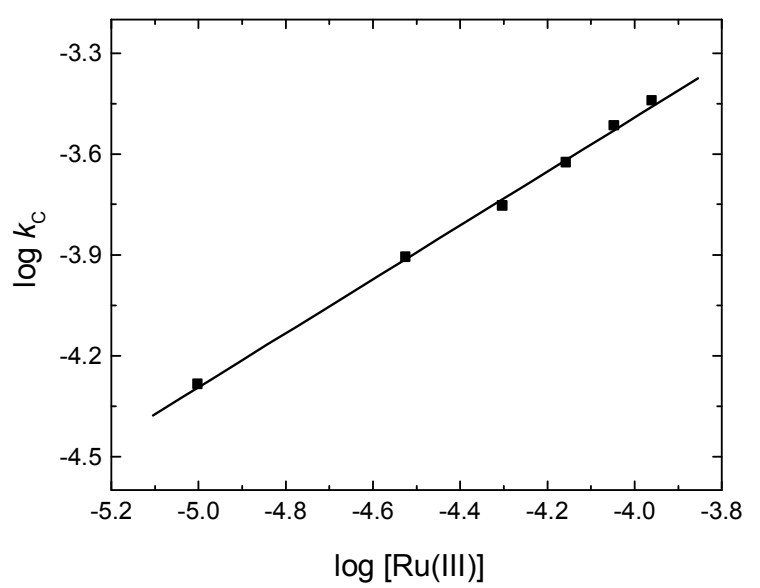

Figure 4. Plot of $\log k_{C}$ versus $\log [R u(I I I)]$ in the Ru(III)-catalyzed oxidation of L-citrulline by HCP in perchloric acid solution. [Cit] $=6.0 x$ $10^{-3},[\mathrm{HCP}]=8.0 \times 10^{-5},\left[\mathrm{H}^{+}\right]=1.0$ and $\mathrm{I}=1.8 \mathrm{~mol} \mathrm{dm}^{-3}$ at $20^{\circ} \mathrm{C}$.

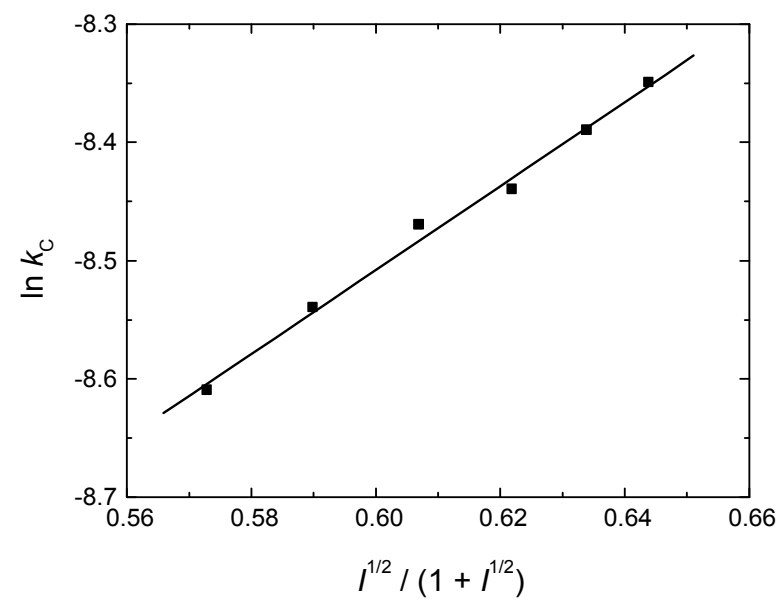

Figure 5. Debye-Hückel plots in the Ru(III)-catalyzed oxidation of Lcitrulline by HCP in perchloric acid solution. $[$ Cit $]=6.0 \times 10^{-3},[H C P]=$ $8.0 \times 10^{-5},\left[H^{+}\right]=1.0$ and $[R u(I I I)]=5.0 \times 10^{-5} \mathrm{~mol} \mathrm{dm}^{-3}$ at $20^{\circ} \mathrm{C}$.

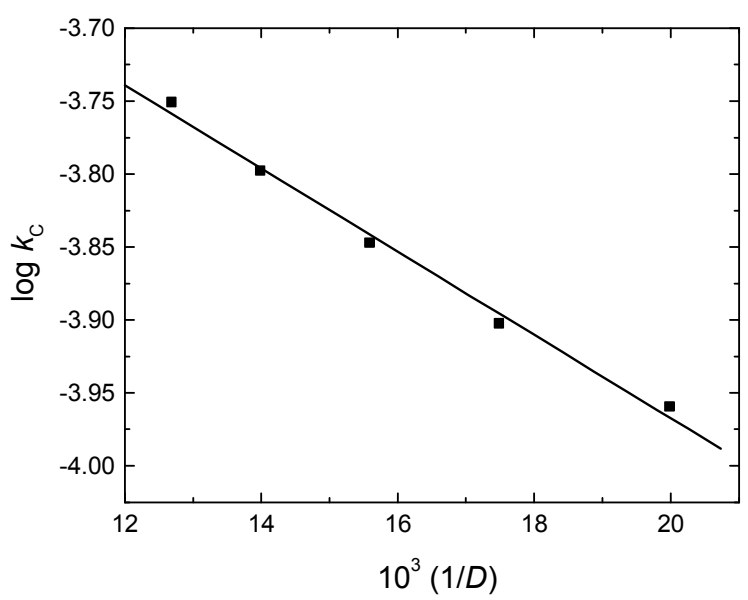

Figure 6. Effect of solvent composition on the observed first order rate constant. Plot of log $k_{C}$ versus $1 / D$ for the Ru(III)-catalyzed oxidation of $L$ citrulline by HCP in perchloric acid solution. [Cit] $=6.0 \times 10^{-3},[H C P]=$ $8.0 \times 10^{-5},\left[H^{+}\right]=1.0,[R u(I I I)]=5.0 \times 10^{-5}$ and $I=1.8 \mathrm{~mol} \mathrm{dm}{ }^{-3}$ at $25^{\circ} \mathrm{C}$.

\subsection{Effect of Temperature}

The rate of $\mathrm{Ru}(\mathrm{III})$-catalyzed oxidation of L-citrulline by HCP in perchloric acid solution was measured at five different temperatures $(288-308 \mathrm{~K})$. The reaction rate was found to increase with raising temperature. The activation parameters of the second order rate constants $\left(k_{2}\right)$ are calculated using Arrhenius and Eyring plots and are listed in Table 2.

Table 2. Activation parameters of $k_{2}$ in the Ru(III)-catalyzed oxidation of Lcitrulline by HCP in perchloric acid solution.

\begin{tabular}{llll}
\hline $\boldsymbol{\Delta} \boldsymbol{S}^{\neq} \mathbf{J} \mathbf{~ m o l}^{-1} \mathbf{K}^{-1}$ & $\boldsymbol{\Delta} \boldsymbol{H}^{\neq,} \mathbf{k J ~ m o l}^{-1}$ & $\boldsymbol{\Delta} \boldsymbol{G}^{\neq}{ }_{\mathbf{2 9 3}} \mathbf{~ k J ~ m o l}^{-1}$ & $\boldsymbol{E}_{\mathrm{a}}^{\neq}, \mathbf{k J ~ m o l}^{-\mathbf{1}}$ \\
\hline-73.22 & 44.21 & 65.66 & 47.30 \\
\hline
\end{tabular}

\subsection{Test for Free Radical Intermediates}

To study the possible intervention of free radicals during the oxidation reaction, the reaction mixture to which a known quantity of acrylonitrile scavenger was initially added was 
kept for $8 \mathrm{~h}$ in an inert atmosphere. On diluting the mixtures with methanol, no white precipitate was formed, thus confirming the absence of free radical intervention in the present reaction.

\section{Discussion}

It was reported $[39,40]$ that the reactive species of $\mathrm{Ru}(\mathrm{III})$ chloride in acid media is $\left[\mathrm{RuCl}_{5}\left(\mathrm{H}_{2} \mathrm{O}\right)\right]^{2-}$ (assigned as $\left.\mathrm{Ru}(\mathrm{III})^{*}\right)$. Also, due to the availability of electron pairs on both oxygen atom of the carboxylate group and nitrogen atom of the amine group in L-citrulline. Within the protolytic L-citrulline system, the carboxylate and amine groups may act as nucleophiles, depending on $\mathrm{pH}$ of the medium. The protolytic group with the highest basicity interacts with the $\mathrm{Ru}$ (III) catalyst. Thus, at low $\mathrm{pH}$ where the amine group is protonated, the carboxylate group should be able to attack $\mathrm{Ru}(\mathrm{III})$. On the other hand, platinum(IV) species in acid medium is present as $\left[\mathrm{PtCl}_{6}\right]^{2-}$, which is assumed to be the principal reactive oxidant [41]. Because platinum(IV) complexes are generally substitution-inert [42], initial complex formation between platinum(IV) and reductant prior to electron transfer can be excluded in reductive-elimination reactions. There are two alternative reaction mechanisms for the oxidation by HCP may be considered. The first mechanism involves a simultaneous two-electron transfer in a single step. The second one involves two successive oneelectron transfer steps. If the transition states of the reductant and/or oxidant are unstable, a simultaneous two-electron transfer mechanism may be suggested, such as that in the oxidation of uranium(IV) by $\left[\mathrm{PtCl}_{6}\right]^{2-}[28]$. In the present study, addition of acrylonitrile monomer to the reaction mixture failed to give polymerized products. It may be that a free radical such as the $\mathrm{Pt}$ (III) species is too short-lived to interact with acrylonitrile to give the polymerized product under our experimental conditions. Consequently, the twoelectron transfer mechanism seems plausible.

The present reaction between HCP and L-citrulline in the presence of small amounts of $\mathrm{Ru}(\mathrm{III})$ catalyst had a stoichiometry of 1:1 with a first order dependence on both $[\mathrm{HCP}]$ and $[\mathrm{Ru}(\mathrm{III})]$, and less than unit orders with respect to both $[\mathrm{Cit}]$ and $\left[\mathrm{H}^{+}\right]$. The observed increase in the reaction rate upon increasing acid concentration suggests protonation of L-citrulline substrate prior to the rate-determining step to form protonated L-citrulline as a more reactive species, which plays the main role in the reaction kinetics [43] as illustrated by step (1) in the mechanistic Scheme 1. The less than unit order with respect to [Cit] suggests formation of an intermediate complex between L-citrulline substrate and $\mathrm{Ru}(\mathrm{III})$ catalyst prior to the reaction with the oxidant, step (2). Complex formation was proved kinetically by the nonzero intercepts of the plots of $[\mathrm{Ru}(\mathrm{III})] / k_{\mathrm{C}}$ versus $1 /[\mathrm{Cit}]$ (Figure 7) [44]. Spectroscopic evidence to support complex formation between L-citrulline and $\mathrm{Ru}(\mathrm{III})$ which obtained from the UV-Vis spectra was the observed appearance of two isosbestic points as shown in Figure 1. Also, the oxidation rate increased upon increasing both ionic strength and dielectric constant of the medium, suggesting that the ratedetermining step of the reaction occurred between two similarly charged ions $[45,46]$.<smiles>[X]C=C[PH+]=COC(=O)C(N)CCCNC(N)=O</smiles>

L-Citrulline

Protonated L-Citrulline

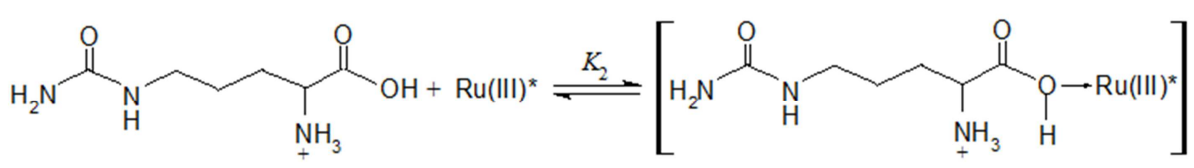

Complex (C)

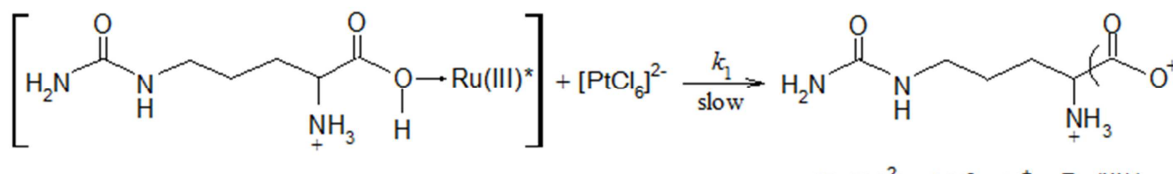

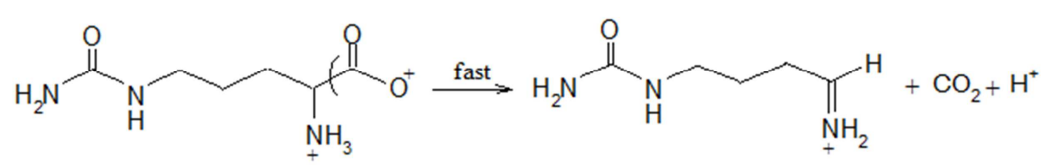

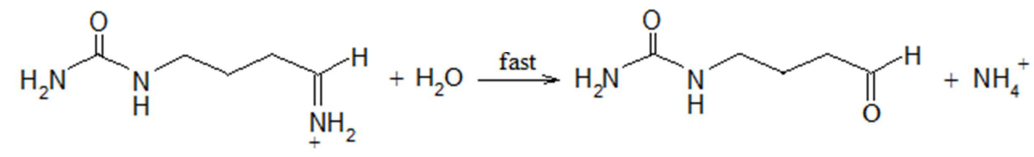


The suggested mechanism shown in Scheme 1 involves combination of the protonated L-citrulline with the reactive species of the catalyst, $\mathrm{Ru}(\mathrm{III})^{*}$, to form an intermediate complex (C). The complex reacts in a slow step with HCP leading to formation of L-citrulline cation with regeneration of the catalyst $\mathrm{Ru}(\mathrm{III})^{*}$, step (3), which rapidly hydrolyze to give rise to the oxidation products of L-citrulline 4(carbamoylamino) butyraldehyde, ammonia and carbon dioxide as illustrated by step (5).

The suggested mechanism leads to the following rate-law expression:

$$
\text { Rate }=\frac{-d[\mathrm{HCP}]}{d t}=\frac{+d[\mathrm{C}]}{d t}=k_{1}[\mathrm{C}][\mathrm{HCP}]
$$

The relationship between the rate of complex formation and the substrate, hydrogen ion, catalyst and oxidant concentrations can be deduced to give the following rate-law expression:

$$
\text { Rate }=\frac{k_{1} K_{1} K_{2}[\mathrm{Cit}]\left[\mathrm{H}^{+}\right][\mathrm{Ru}(\mathrm{III})][\mathrm{HCP}]}{\left(1+K_{1}\left[\mathrm{H}^{+}\right]+K_{1} K_{2}\left[\mathrm{H}^{+}\right][\mathrm{Ru}(\mathrm{III})]\right)\left(1+K_{1} K_{2}[\mathrm{Cit}]\left[\mathrm{H}^{+}\right]\right)}
$$

In view of low concentration of $[\mathrm{Ru}(\mathrm{III})]$ used, the term $K_{1} K_{2}\left[\mathrm{H}^{+}\right][\mathrm{Ru}(\mathrm{III})]$ in the denominator can be neglected. Therefore, Eq. (7) becomes,

$$
\text { Rate }=\frac{k_{1} K_{1} K_{2}[\mathrm{Cit}]\left[\mathrm{H}^{+}\right][\mathrm{Ru}(\mathrm{III})][\mathrm{HCP}]}{1+K_{1}\left[\mathrm{H}^{+}\right]+K_{1} K_{2}[\mathrm{Cit}]\left[\mathrm{H}^{+}\right]}
$$

Under pseudo-first order condition,

$$
\text { Rate }=\frac{-d[\mathrm{HCP}]}{d t}=k_{\mathrm{C}}[\mathrm{HCP}]
$$

Comparing Eqs. (8) and (9) and rearrangement, we obtain,

$$
\begin{gathered}
\frac{[\mathrm{Ru}(\mathrm{III})]}{k_{\mathrm{C}}}=\left(\frac{1}{k_{1} K_{1} K_{2}\left[\mathrm{H}^{+}\right]}+\frac{1}{k_{1} K_{2}}\right) \frac{1}{[\mathrm{Cit}]}+\frac{1}{k_{1}} \\
\frac{[\mathrm{Ru}(\mathrm{III})]}{k_{\mathrm{C}}}=\left(\frac{1}{k_{1} K_{1} K_{2}[\mathrm{Cit}]}\right) \frac{1}{\left[\mathrm{H}^{+}\right]}+\frac{1}{k_{1} K_{2}[\mathrm{Cit}]}+\frac{1}{k_{1}}
\end{gathered}
$$

According to Eqs. (10) and (11), the plots of $[\mathrm{Ru}(\mathrm{III})] / k_{\mathrm{C}}$ versus $1 /[\mathrm{Cit}]$, at constant $\left[\mathrm{H}^{+}\right]$, and $[\mathrm{Ru}(\mathrm{III})] / k_{\mathrm{C}}$ against $1 /\left[\mathrm{H}^{+}\right]$, at constant [Cit], should be linear with positive intercepts on $[\mathrm{Ru}(\mathrm{III})] / k_{\mathrm{C}}$ axes. The experimental results satisfied this requirement as shown in Figures 7 and 8. From the slopes and intercepts of these Figures, the values of the rate constant of the slow step $\left(k_{1}\right)$ and the equilibrium constants involved in the first two steps of the mechanistic Scheme $1\left(K_{1} \& K_{2}\right)$ can be evaluated.

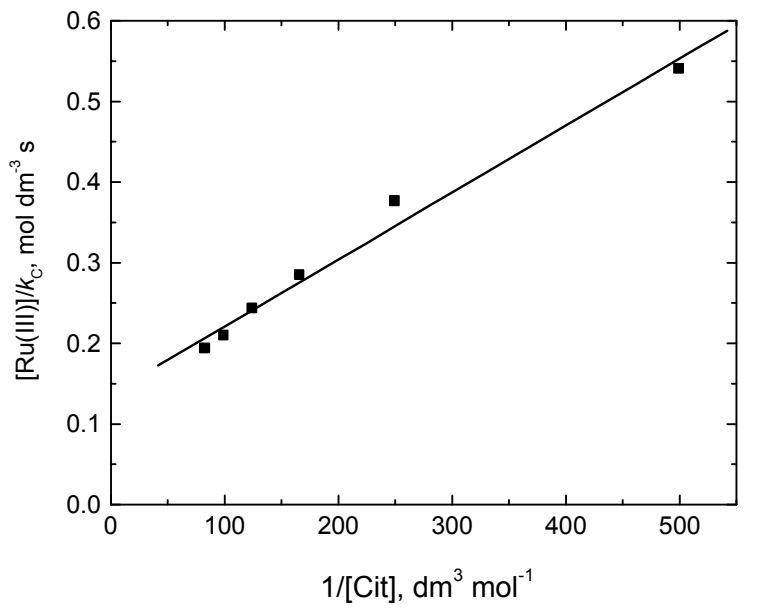

Figure 7. Plot of $[R u(I I I)] / k_{C}$ versus $1 /[C i t]$ in the Ru(III)-catalyzed oxidation of L-citrulline by HCP in perchloric acid solution. $[\mathrm{HCP}]=8.0 \mathrm{x}$ $10^{-5},\left[\mathrm{H}^{+}\right]=1.0$ and $\mathrm{I}=1.8 \mathrm{~mol} \mathrm{dm} \mathrm{m}^{-3}$ at $20^{\circ} \mathrm{C}$.

The obtained negative value of $\Delta S^{\ddagger}$ indicates that there is a decrease in the randomness during the oxidation process. This leads to the formation of compacted intermediate complex and such activated complex is more ordered than the reactants due to loss of degree of freedom [47, 48]. Again, the negative values of both $\Delta H^{\ddagger}$ and $\Delta G^{\neq}$indicate the exothermic formation of the intermediate and its spontaneity, respectively.

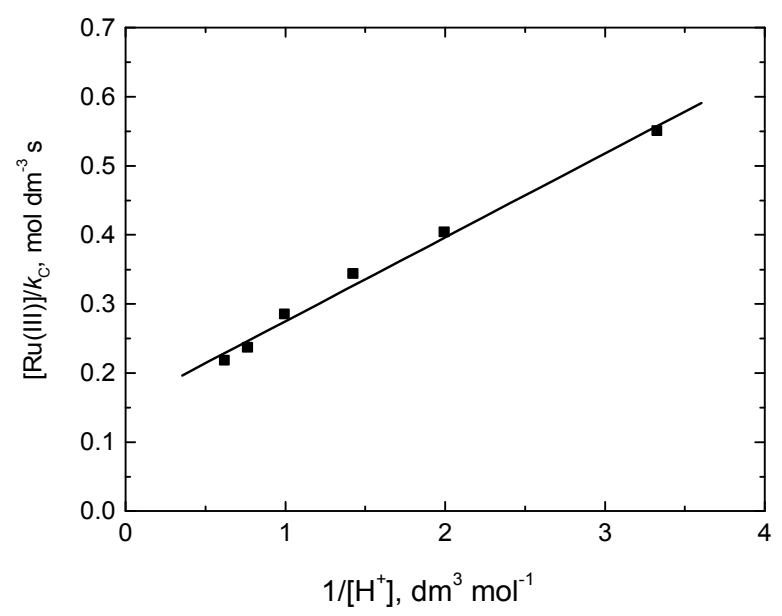

Figure 8. Plot of $[R u(I I I)] / k_{C}$ versus $1 /\left[H^{+}\right]$in the Ru(III)-catalyzed oxidation of L-citrulline by HCP in perchloric acid solution. [Cit] $=6.0 x$ $10^{-3},[\mathrm{HCP}]=8.0 \times 10^{-5}$ and $\mathrm{I}=1.8 \mathrm{~mol} \mathrm{dm}^{-3}$ at $20^{\circ} \mathrm{C}$.

\section{Conclusions}

The reaction between L-citrulline and hexachloroplatinate (IV) in perchloric acid solution was very slow in the absence of $\mathrm{Ru}$ (III) catalyst. Plausible mechanistic scheme of the catalyzed reaction has been proposed. The final oxidation products of L-citrulline was identified as 4(carbamoylamino) butyraldehyde, ammonia and carbon dioxide. 


\section{References}

[1] Senagar SKS, Yadav BS (1988) Kinetics and mechanism of copper (II)-catalyzed oxidation of asparagine by sodium Nchloro-p-toluene sulphonamide in alkaline media. J. Indian Chem. Soc. 65: 88-90.

[2] Sanjeevagowda TP, Mahantesh AA, Abdulazizkhan LH (2008) Oxidative deamination and decarboxylation of Lasparagine by the aqueous alkaline diperiodato-nickelate (IV) complex. J. Solution Chem. 37: 1795-180.

[3] Khalid MAA (2007) Oxidative kinetics of amino acids by peroxydisulfate: Effect of dielectric constant, Arabian J. Sci. Eng. 33: 199-210.

[4] Anweting IB, Iyun JF, Idris SO (2012) Kinetics and mechanistic approach to the oxidation of L-tryptophan by permanganate ion in aqueous acidic medium. Adv. Appl. Sci. Res. 3: 3401-3409.

[5] Sharma VK, Sharma K, Tiwari PS, Khare D (2011) Mechanism of quinquevalent vanadium oxidation of Ltyptophan in sulphuric acid medium. Int. J. Pharm. Life Sci. 2: 1223-1225.

[6] Shetti NP, Hosamani RR, Nandibewoor ST (2009) Kinetic and mechanistic investigations on oxidation of L-tryptophan by diperiodatocuprate (III) in aqueous alkaline medium. Open Catal. J. 2: 130-139.

[7] Fawzy A, Ashour SS, Musleh MA, Hassan RM, Asghar BH (2015) Kinetics and mechanistic approach to the chromic acid oxidation of L-tryptophan with a spectral detection of chromium (III) product. J. Saudi Chem. Soc. in press.

[8] Asghar BH, Altass HM, Fawzy A (2015) Copper (II) catalysis for oxidation of L-tryptophan by hexacyanoferrate (III) in alkaline medium: a kinetic and mechanistic approach. J. Saudi. Chem. Soc. in press.

[9] Fawzy A (2015) Palladium (II)-catalyzed oxidation of Ltryptophan by hexacyanoferrate (III) in perchloric acid medium: a kinetic and mechanistic approach. J. Chem. Sci. In press.

[10] Fawzy A (2014) Influence of copper (II) catalyst on the oxidation of L-histidine by platinum (IV) in alkaline medium: a kinetic and mechanistic study. Transition Met. Chem. 39: 567-576.

[11] Fawzy A (2015) Kinetics and mechanistic approach to the oxidative behavior of biological anticancer platinum (IV) complex towards L-asparagine in acid medium and the effect of copper (II) catalyst. Int. J. Chem. Kinet. 47: 1-12.

[12] Fawzy A, Asghar BH (2015) Kinetics and mechanism of uncatalyzed and silver (I)-catalyzed oxidation of L-histidine by hexachloroplatinate (IV) in acid medium. Transition Met. Chem. 40: 287-295.

[13] Asghar BH, Altass HM, Fawzy A (2015) Transition metal ions-catalyzed oxidation of L-asparagine by platinum (IV) in acid medium: a kinetic and mechanistic study. Transition Met. Chem. 40: 587-594.

[14] Fawzy A, Zaafarany IA (2015) Kinetic and mechanistic investigation on the zirconium (IV)-catalyzed oxidation of Lhistidine by hexachloroplatinate (IV) in acid medium. Chem. Sci. Rev. Lett. 4: 608-618.
[15] Fawzy A, Zaafarany IA (2015) Mechanistic investigation of copper (II)-catalyzed oxidation of L-asparagine by hexachloroplatinate (IV) in aqueous alkaline medium: a kinetic approach. J. Multidisc. Eng. Sci. Technol. 2: 10381045 .

[16] Asghar BH, Altass HM, Fawzy A (2016) Silver (I)-catalysis of oxidative deamination and decarboxylation of Lasparagine and L-histidine by platinum (IV) in perchloric acid solutions: a comparative kinetics study. J. Env. Chem. Eng. 4: 617-623.

[17] Fawzy A, Ashour SS, Musleh MA (2014) Base-catalyzed oxidation of L-asparagine by alkaline permanganate and the effect of alkali-metal ion catalysts: Kinetics and mechanistic approach, React. Kinet. Mech. Catal. 111: 443-460.

[18] Fawzy A, Ashour SS, Musleh MA (2014) Kinetics and mechanism of oxidation of L-histidine by permanganate ions in sulfuric acid medium, Int. J. Chem. Kinet. 46: 370-381.

[19] Nos2 - Nitric Oxide Synthase. Uniprot.org. Uniprot Consortium. Retrieved 10 February 2015.

[20] Keage MC, Kelland MJ, Neidles LR, Warning MJ, ed. (1993) Molecular Aspects of Anticancer Drug DNA Interactions, vol. 1, CRC Press, New York, NY, USA.

[21] Lemma K, Sargeson A, Elding LI (2000) Kinetics and mechanism for reduction of oral anticancer platinum (IV) dicarboxylate compounds by L-ascorbate ions. J. Chem. Soc. Dalton Trans. 7: 1167-1172.

[22] Weiss RP, Christian MC (1993) New cisplatin analogues in development. A review. Drugs 46: 360-377.

[23] Lemma K, Shi T, Elding LI (2000) Kinetics and mechanism for reduction of the anticancer prodrug trans, trans, trans$\left[\mathrm{PtCl}_{2}(\mathrm{OH})_{2}\left(\mathrm{c}-\mathrm{C}_{6} \mathrm{H}_{11} \mathrm{NH}_{2}\right)\left(\mathrm{NH}_{3}\right)\right]$ (JM335) by thiols, Inorg. Chem. 39: 1728-1734.

[24] Beattie K, Basolo F (1967) Reduction of some platinum (IV) complexes with tris (bipyridine) chromium (II) ion. Inorg. Chem. 6: 2069-2073.

[25] Beattie K, Basolo F (1971) Two-electron inner-sphere reduction of chloropentaammine-platinum (IV) ion by aquochromium (II) ion. Inorg. Chem. 10: 486-491.

[26] Moodley KG, Nicol MJ (1977) Kinetics of the reduction of platinum (IV) by tin (II) and copper (I) in aqueous chloride solutions. J. Chem. Soc., Dalton Trans. 239-243.

[27] Sen Gupta KK, Das S, Sen Gupta S (1988) Kinetics and mechanism of the oxidation of thiosulphate by hexachloroplatinate (IV). Transition Met. Chem. 13: 155-159.

[28] Hassan RM, Kojima T, Fukutomi T (1982) Kinetics of the oxidation of uranium (IV) by hexachloroplatinate (IV) in aqueous solution. VI International symposium on solutesolute-solvent interactions. Japan, pp. 113

[29] Choi S, Filotto C, Bisanzo M, Delaney S, Lagasee D, Whitworth JL, Jusko A, Li C, Wood NA, Willingham J, Schwenker A, Spaulding K (1988) Reduction and anticancer activity of platinum (IV) complexes. Inorg. Chem. 37: 25002504.

[30] Sen Gupta KK, Begum BA, Ghosh SP (1998) Reactivities of osmium (VIII), iridium (IV) and platinum (IV) towards glycolaldehyde. Transition Met. Chem. 23: 295-299. 
[31] Pal B, Sen Gupta KK (2000) Kinetics and mechanism of hexachloroplatinate (IV) reduction by some neutralized alphahydroxy acids in a carbonate-hydrogencarbonate buffer medium. Bull. Chem. Soc. Jpn. 73: 553-560.

[32] Pal B, Sen Gupta KK, Sen PK (2005) Oxidative cleavage of $\alpha$, $\beta$-unsaturated compounds by pentachlorohydroxoplatinate (IV) in alkaline medium. Transition Met. Chem. 30: 593-600.

[33] Sen Gupta KK, Sen PK, Sen Gupta S (1977) Kinetics of oxidation of hydrazinium ion by platinum (IV). Inorg. Chem. 16: 1396-1399.

[34] Sen Gupta KK, Sen PK (1977) Kinetics of the oxidation of hydroxylamine by platinum (IV). J. Inorg. Nucl. Chem. 39: 1651-1653.

[35] Shukla R, Upadhyay SK (2008) Non-ionic micellar inhibition on the rate of oxidation of L-histidine by alkaline hexacyanoferrate (III). Indian J. Chem. 47A: 551-555.

[36] Georgieva M, Andonovski B (2003) Determination of platinum (IV) by UV spectrophotometry, Anal. Bioanal. Chem. 375: 836-839.

[37] Vogel AI (1973) Text book of practical organic chemistry, 3rd ed., ELBS Longman, London, p. 332 and 679.

[38] Feigl F (1957) Spot Tests in Organic Analysis, Elsevier, New York, NY, USA.

[39] Fawzy A, Altass HM (2016) Ruthenium (III)-catalyzed oxidation of alginate and pectate biopolymers by chromic acid in aqueous perchlorate solutions: A comparative kinetic study. Transition Met. Chem. 41: 115-124.
[40] Griffith WP (1967) The chemistry of rare platinum metals, Interscience Publishers, pp. 141.

[41] Kramer J, Koch KR (2006) ${ }^{195} \mathrm{Pt}$ NMR Study of the speciation and preferential extraction of Pt (IV)-mixed halide complexes by diethylenetriamine-modified silica-based anion exchangers, Inorg. Chem. 45: 7843-7855.

[42] Mason WR (1972) Platinum (II)-catalyzed substitutions of platinum (IV) complexes. Coord. Chem. Rev. 7: 241-255.

[43] Martell AE, Smith RM (1974) In: Critical Stability Constants. vol. I. Plenum Press, New York, pp. 321.

[44] Michaelis L, Menten ML (1913) The kinetics of invertase action. Biochem. Z 49: 333-369.

[45] Amis ES (1966) Solvent Effect on Reaction Rates and Mechanism, Academic Press, New York, pp. 28.

[46] Rochester CH (1971) Progress in Reaction Kinetics. Pergamon Press, Oxford, 1971, pp. 145.

[47] Hicks KW, Toppen DL, Linck RG (1972) Inner-sphere electron-transfer reactions of vanadium (II) with azidoamine complexes of cobalt (III). Inorg. Chem. 11: 310-315.

[48] Weissberger A (1974) In Investigation of rates and mechanism of reactions in techniques of chemistry, John Wiley \& Sons, pp. 421 . 